\title{
EDIFICIO EN LAS CALLES EDISON Y FRANCISCO SILVELA, MADRID (ESPAÑA)
}

\author{
(BUILDING IN THE EDISON AND FRANCISCO SILVELA STREETS. MADRIDISPAIN)
}

Alberto de Comenge, Arquitecto

$131-148$

RESUMEN

Sobre un solar de $7.317 \mathrm{~m}^{2}$, entre las calles de Francisco Silvela, Pedro de Valdivia, Edison y Glorieta de López de Hoyos, se levanta el edificio Edison con forma de estrella de tres brazos y que consta de ocho plantas sobre rasante destinadas para oficinas y dos bajos rasante para

aparcamientos e instalaciones. La concentración del volumen ha permitido dejar una gran superficie para zona ajardinada.

\section{SUMMARY}

On a site with a surface of 7,317 $\mathrm{m}^{2}$, among the streets of Madrid Francisco Silvela, Pedro of Valdivia, Edison and Glorieta de López de Hoyos, raises the building "Edison" with the size of a three arms star and 8 levels over the ground assigned for office purposes and 2 under ground for parking and installations. The volumen concentrations has allowed to leave beside a great garden area.
La responsabilidad del proyecto se centró, casi como en tiempos de estudiantes en la Escuela de Arquitectura, en un tema libre. Un edificio de oficinas en un solar muy extenso cuya Ordenanza permitía numerosas soluciones en cuanto a su concepción, forma, alturas, etcétera...

Durante numerosas reuniones se presentaron soluciones que se discutieron ampliamente con mis compañeros de proyecto, Rafael Comenge e Ignacio Blanco. Por un lado, la forma alargada del solar parecía favorecer una estructura paralela a la calle Francisco Silvela; por otro, la mayor dignidad de la calle Edison, aconsejaba concentrar el volumen de edificación cerca de la Glorieta de López de Hoyos.

La idoneidad de una planta en forma de estrella para un edificio de estas características, unido a la estética de la solución, nos hizo adoptarla. Lo elemental de un edificio de oficinas en lo que se refiere a su tratamiento interior excluye todo lo superfluo y lo que se aparte de lo estrictamente funcional.

Las plantas al quedar diáfanas a merced de arquitectos o decoradores de los futuros inquilinos para crear sus propias oficinas que cumplan con cada programa de necesidades, limita la labor del arquitecto autor del edificio a dos facetas principales: la tecnológica co- rrespondiente a una obra que casi es una fábrica para crear un ambiente propicio para el trabajo, y la estética, que afecta fundamentalmente a su aspecto exterior.

En la vertiente técnica, una vez adoptada una solución correcta, el arquitecto necesita colaborar con otros técnicos especialistas en cada grupo de instalaciones. La confianza en empresas instaladoras de primera línea, es básica para obtener el nivel requerido. El trabajo en equipo se hace necesario y el arquitecto debe perder protagonismo e integrarse en la consecución del objetivo común de obtener el menor coste dentro de una calidad razonable.

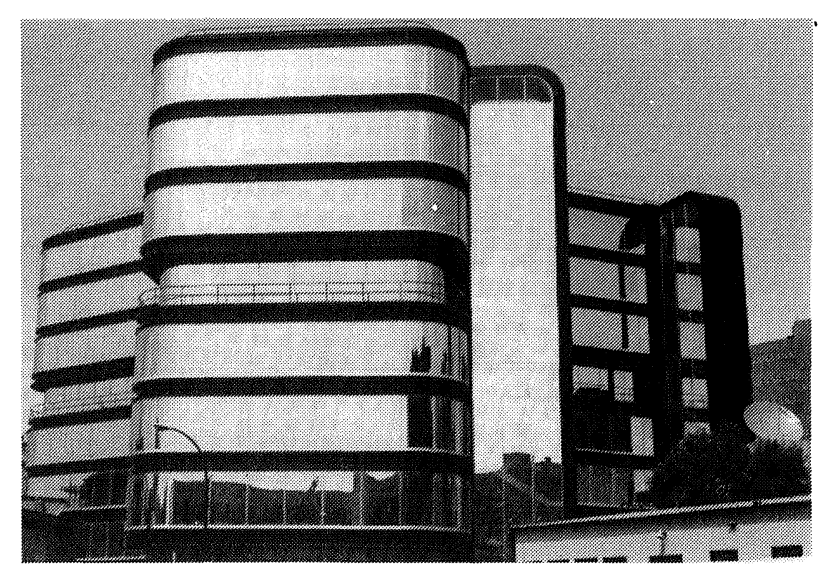



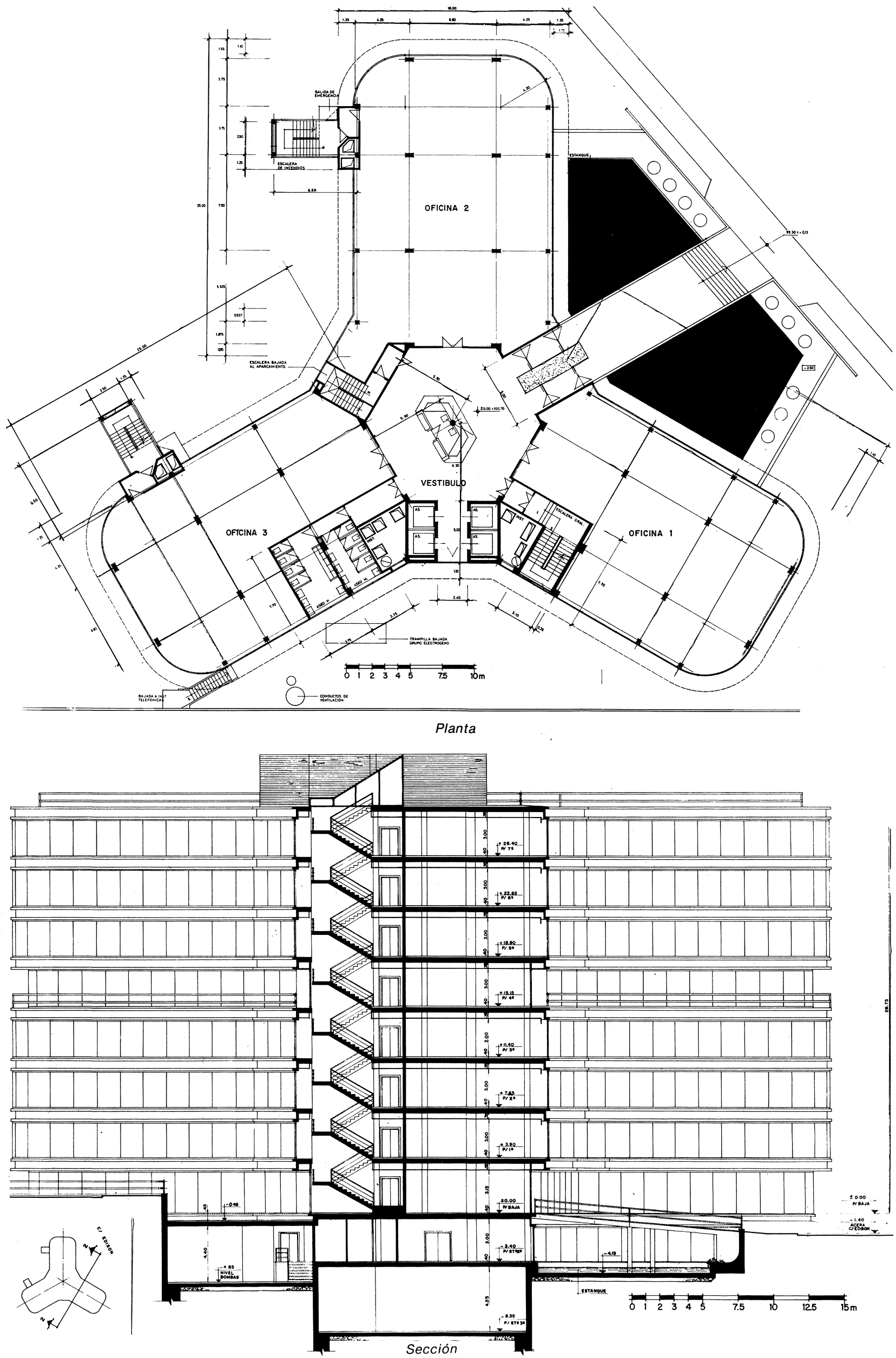


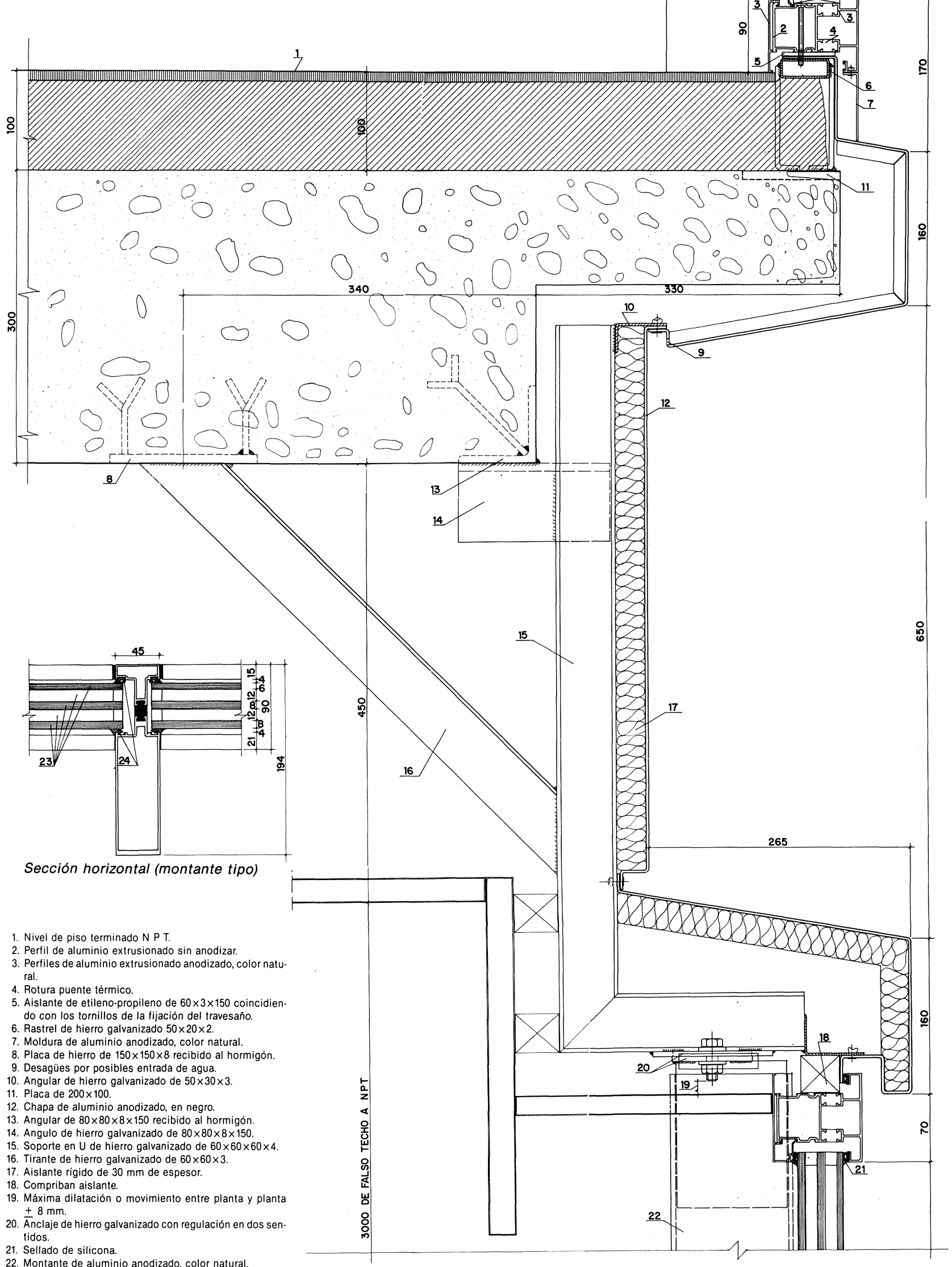

22. Montante de aluminio anodizado, color natural.

23. Vidrio climalit triple formado por reflectasol de $6 \mathrm{~mm}$ al

exterior y de $8 \mathrm{~mm}$ al interior.

24. Juntas continuas de etileno-propileno. 


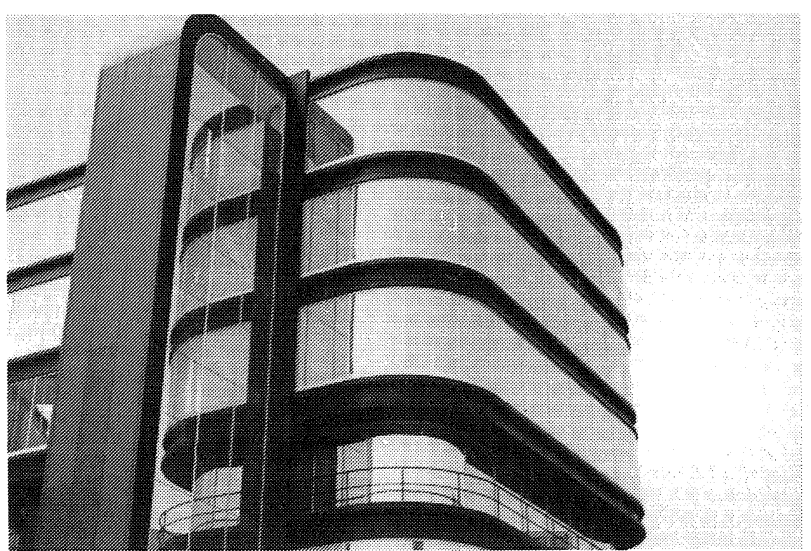

A nosotros, en general, nos tienta más lo que afecta a las condiciones estéticas donde nuestra labor se hace personal y no admite colaboraciones indiscriminadas. Nuestra obra adquiere la responsabilidad de compartir el paisaje urbano y va a formar parte de nuestra ciudad dando, en un lugar estratégico, carácter a su personalidad.

La plaza de López de Hoyos ha adquirido con el tiem. po mayor categoria y era preciso dignificarla con un edi. ficio de prestigio. El paso elevado de la calle Francisco Silvela, por donde discurre una de las rondas de mayor tráfico de Madrid, también merecia un examen profundo para crear un hito singular en su entorno.

"El edificio puede ser un aspa que momentáneamente ha dejado de girar y que sería el motor que acciona el tráfico que discurre tangencialmente." Esta sería la inspiración que ha dado paso a las concepciones formales de su diseño. La planta de estrella que redondea sus esquinas da sensación de aspa y al remeter la planta intermedia se refuerza aún más su contorno.

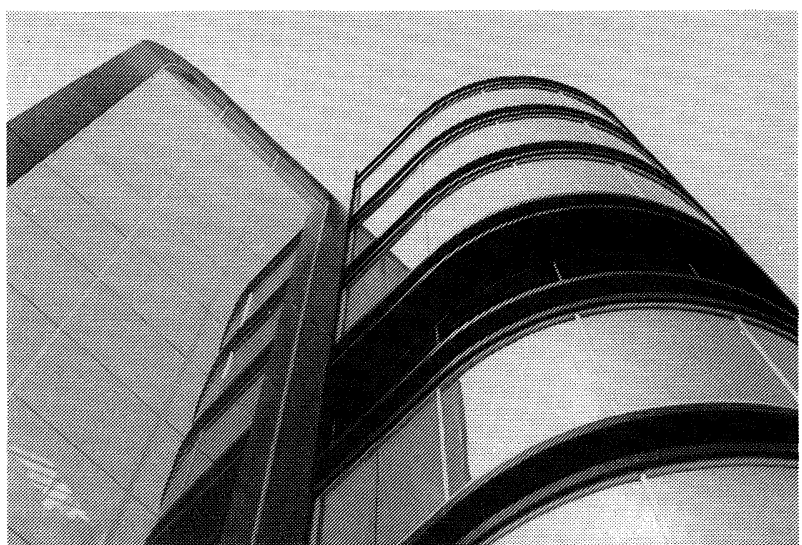

La otra consideración de importancia fue darle el acceso por la calle Edison. Aparte de ser la orientación más digna, ofrece indudables ventajas funcionales para la entrada de vehículos a su aparcamiento. Por esta caIle la fachada es más tranquila y con el desnivel del terreno permite abrir el sótano al estanque que, a modo de foso, flanquea la entrada principal. La pasarela da acceso al edificio a modo de un puente levadizo que pretendiera hacerlo inexpugnable.

Las escaleras de incendio, que son exentas, culminan en la última planta de forma circular para que todas las perspectivas sean redondas y semejantes. El reflectasol de sus laterales refleja la fachada del edificio, intentando manifestar con la insistencia que produce su aparente continuidad nuestro agrado con su diseño.

Estos elementos verticales apoyan la fachada posterior y dan cierta asimetría que rompe un conjunto excesivamente regular. La mejor perspectiva del edificio es, posiblemente, desde ahi, al comienzo de la calle Edison.

\section{publicación del i.e.t.c.c.}

\begin{tabular}{|l|l|} 
Jornadas Científico-Técnicas \\
sobre la Construcción y el Cemento \\
Comemoracion del \\
Cn un deseo de informar eficazmente sobre la situación actual en el campo de la \\
Construcción y del Cemento, los investigadores y técnicos agruparon sus exposicio- \\
nes en los siguientes tres grandes temas: Materiales de Construcción, Tecnología de \\
la Construcción, y Normativa-Calidad-Cooperación. Se consiguió de esta manera pre- \\
sentar una panorámica real de la Investigación y Desarrollo en la materia. \\
Consideramos que el libro es de interés para cuantos siguen la evolución de la Cons- \\
trucción en general y que en muchos casos encontrarán estudios, en profundidad, de \\
temas y problemas puntuales. \\
Esta obra se publicó con motivo de la celebración de las Bodas de Oro del Instituto \\
Eduardo Torroja - Noviembre 1984 y en sus 283 páginas se recogen, de forma crono- \\
lógica, las 35 intervenciones, conferencias y comunicaciones de los numerosos espe- \\
cialistas - nacionales y extranjeros- que tomaron parte.
\end{tabular}

